\title{
Análise dos serviços de saneamento básico e a incidência de casos de Chikungunya no Bairro da Matinha em Santarém (PA)
}

O objetivo do trabalho foi analisar a qualidade dos serviços de saneamento básico e a sua relação com os casos de Chikungunya no Bairro da Matinha, localizado no município de Santarém (PA). Para isso, foram utilizados dados primários e secundários, resultantes da aplicação de 183 questionários para a população residente no bairro, realização de visitas in loco e acesso ao banco de dados dos órgãos de saúde do município relacionados à incidência de Chikungunya. No Bairro da Matinha, foram notificados 25 casos de Chikungunya, sendo 18 confirmados, sendo o bairro com maior incidência da doença em Santarém. Nas ruas identificadas com maior número de infectados, constatou-se a precariedade das vias, com presença de esgoto doméstico e resíduos sólidos domiciliares. Observou-se também a existência de terrenos baldios que são utilizados como depósitos inadequados de resíduos que servem como criadouros do mosquito Aedes Aegypti. Os resultados evidenciaram que a maioria dos moradores possui o ensino fundamental incompleto; $32 \%$ dos entrevistados afirmaram a existência de terrenos baldios; e $95 \%$ acham que esses terrenos contribuem para a disseminação de doenças; $42 \%$ dos entrevistados não souberam definir saneamento básico, o que pode compromete as ações de prevenção e controle de doenças endêmicas. Diante do exposto, conclui-se que as condições inadequadas da infraestrutura de saneamento básico contribuem para o alto índice de casos de febre Chikungunya no bairro, o que evidencia a necessidade de maior atuação do poder público e a conscientização/sensibilização da população local.

Palavras-chave: Saúde Pública; Aedes Aegypti; Doenças endêmicas; Prevenção.

\section{Analysis of basic sanitation services and the incidence of Chikungunya cases in Bairro da Matinha in Santarém (PA)}

\begin{abstract}
The objective of this study was to analyze the quality of basic sanitation services and their relationship with the cases of Chikungunya in Bairro da Matinha, located in the municipality of Santarém (PA). For this, primary and secondary data were used, resulting from the application of 183 questionnaires to the population residing in the neighborhood, conducting on-site visits and access to the municipal health agencies database related to the incidence of Chikungunya. In Matinha Neighborhood, 25 cases of Chikungunya were reported, 18 confirmed, being the neighborhood with the highest incidence of the disease in Santarém. In the streets identified with the highest number of infected, the precariousness of the roads was found, with the presence of domestic sewage and household solid waste. There was also the existence of wastelands that are used as inadequate waste deposits that serve as breeding grounds for the Aedes Aegypti mosquito. The results showed that most residents have incomplete elementary school; $32 \%$ of respondents stated the existence of vacant land; and $95 \%$ think these lands contribute to the spread of disease; $42 \%$ of respondents did not know how to define basic sanitation, which can compromise the prevention and control of endemic diseases Given the above, it is concluded that the inadequate conditions of basic sanitation infrastructure contribute to the high rate of cases of Chikungunya fever in the neighborhood, which highlights the need for greater action by the government and the awareness/local population.
\end{abstract}

Keywords: Public health; Aedes Aegypti; Endemic diseases; Prevention.

Topic: Epidemiologia e Saúde Ambiental

Reviewed anonymously in the process of blind peer.
Received: 15/08/2018

Approved: 21/08/2018
Cineide Oliveira Silva

Universidade Federal do Oeste Pará, Brasi

http://lattes.cnpq.br/5752804386570710

cineide133@gmail.com

Maria Aparecida Miranda

Universidade Federal do Oeste do Pará, Brasi

http://lattes.cnpq.br/3217265310197881

cidamiranda82@gmail.com

Diani Fernanda da Silva Less (id

Universidade Federal do Oeste do Pará, Brasil

http://lattes.cnpq.br/2305500880087819

http://orcid.org/0000-0002-1197-3583

diani.less@ufopa.edu.br

DOI: 10.6008/CBPC2179-6858.2018.006.0015
Referencing this:

SILVA, C. O.; MIRANDA, M. A.; LESS, D. F. S.. Análise dos serviços de saneamento básico e a incidência de casos de Chikungunya no Bairro da Matinha em Santarém (PA). Revista Ibero Americana de Ciências Ambientais, v.9, n.6, p.133-146, 2018. DOI:

http://doi.org/10.6008/CBPC2179-6858.2018.006.0015 


\section{INTRODUÇÃO}

No Brasil, o saneamento básico é um direito assegurado pela Constituição e definido pela Lei no 11.445/2007. Essa lei estabelece as diretrizes nacionais para o saneamento básico e o conceitua como o conjunto dos serviços, infraestruturas e instalações operacionais de abastecimento de água, esgotamento sanitário, limpeza urbana, drenagem urbana, manejos de resíduos sólidos e de águas pluviais (BRASIL, 2007).

Segundo a Organização Mundial da Saúde, saneamento é o controle de todos os fatores do meio físico, que exercem ou podem exercer efeitos nocivos sobre o bem-estar físico, mental e social do indivíduo, sendo que a própria OMS define saúde como o estado de completo bem estar físico, social e mental, e não apenas a ausência de doença. De outra forma, pode-se dizer que saneamento caracteriza o conjunto de ações socioeconômicas que tem por objetivo alcançar salubridade ambiental.

Entende-se, ainda, como salubridade ambiental, o estado de higidez (estado de saúde normal) em que vive a população urbana e rural, tanto no que se refere a sua capacidade de inibir, prevenir ou impedir a ocorrência de endemias ou epidemias veiculadas pelo meio ambientes, quanto ao seu potencial de promover o aperfeiçoamento de condições mesológicas (que diz respeito ao clima ou ambiente) favoráveis ao pleno gozo de saúde e bem-estar (GUIMARÃES et al., 2007).

Em termos de desequilíbrio ambiental, Pereira et al. (2013) aponta que o adensamento urbano desordenado vem acarretando condições ecológicas favoráveis à transmissão dos vírus da dengue, pela grande fonte de indivíduos suscetíveis e infectados, concentrados em áreas restritas com passivos estruturais e ambientais. Segundo Corrêa et al. (2013), em um estudo desenvolvido na cidade de Santarém (PA), os níveis de infestação do Aedes aegypti estão associados com a ausência de infraestrutura urbana e de saneamento associados principalmente, ao abastecimento de água e coleta de resíduos sólidos, sendo tais fatores fundamentais para a proliferação do vetor a partir de potenciais criadouros como pneus, calhas, vasos de plantas, caixas d'água, independentemente da proximidade do local ao centro ou as áreas periféricas.

O rápido aumento populacional, associado à falta de infraestrutura habitacional nas áreas urbanas, tem contribuído para o crescimento desordenado dos bairros em Santarém, como é o caso do Bairro da Matinha, alvo deste estudo. Situações como estas trazem consigo diversos problemas ambientais e sociais devido a carência de serviços adequados de saneamento básico, educação e saúde que venha a suprir as necessidades da população que habita o local. No Bairro da Matinha, a ocorrência de casos de dengue é alta, sendo frequentemente divulgado na mídia local. Supõe-se que os principais agentes causadores desta problemática são o crescimento populacional aliado à falta de estruturas de saneamento, principalmente de drenagem urbana, gerenciamento de resíduos sólidos e a má condição das habitações.

Nesse sentido, o presente trabalho se propõe a analisar a relação entre a qualidade dos serviços de saneamento, condições de habitação e a o alto número de casos detectados de arbovirose (Chikungunya) no Bairro da Matinha. Identificar esta relação e as consequências da urbanização desordenada da população é fundamental para o desenvolvimento de políticas públicas voltadas a promoção da qualidade de vida e para a mobilização da população local em busca de melhorias nos serviços públicos ofertados. 


\section{REVISÃO TEÓRICA}

\section{Urbanização desordenada}

De acordo com a Constituição Federal de 1988, em seu art. 30, VII, atribui-se aos municípios competências para promover um a adequado ordenamento territorial, mediante planejamento e controle do uso, do parcelamento e da ocupação do solo urbano (BRASIL, 1988). Por este motivo, é importante que os municípios arquitetem a ocupação e o uso do solo, considerando as potencialidades e fragilidades de seus territórios.

Philippi Junior (2005) caracteriza o ambiente urbano com as seguintes características: alta densidade demográfica; relação desproporcional entre o ambiente construído e ambiente natural; importação de energia para manter o ecossistema em funcionamento; elevado volume de resíduos gerados, sendo estes os principais atributos do ecossistema urbano. Estas características trazem a esse ambiente um desequilíbrio dos sistemas naturais com ciclos biogeoquímicos, taxas de recarga de aquíferos por infiltração, perturbação de fauna e contaminação de recursos hídricos superficiais.

De acordo com Robaina et al. (2010), a acelerada expansão urbana ocorrida nas últimas décadas, associada à incapacidade do governamental no atender a demanda de moradias, levou a população, principalmente a de baixa renda, a ocupar áreas sujeitas a processos de dinâmica superficial desencadeadores de risco, como planícies de inundação e encostas de morros, onde dificilmente serviços básicos de saneamento e limpeza pública podem ser considerados satisfatórios.

O processo de urbanização desordenada agrava o quadro de exclusão social, e tem impacto no ambiente, trazendo como consequências deslizamentos motivados pela remoção da cobertura vegetal de encostas, impermeabilização da superfície e disseminação de vetores (RIBEIRO et al., 2011; SANTOS, 2012). Em estudos, Saraiva et al. (2009) demonstra perfeitamente as consequências do processo de expansão caótico atual, alterando o perfil epidemiológico de doenças consideradas rurais, como a malária e febre amarela, agora tornam-se urbanas influenciado por alteração do meio ambiente decorrente de ocupação desordenada da população, transformando esse processo em um problema de saúde pública grave considerando os padrões atuais do país no combate ao desordenamento urbano e doenças relacionadas a ele.

\section{A influência dos serviços de saneamento no ambiente urbano}

A qualidade de vida da população deve ser uma das prioridades buscadas pela administração pública no desenvolvimento das novas fronteiras de expansão das áreas urbanas. Esta qualidade de vida, porém, é altamente dependente das variáveis relacionadas à ocupação do meio físico, principalmente a densidade populacional (ARAGÃO et al., 2017). Um dos problemas causados pela urbanização é o processo de impermeabilização do solo através de telhados, ruas, calçadas e pátios, entre outros. A impermeabilização não planejada das áreas urbanas é responsável por alterações significativas na hidrologia local, visto que ocorre a grande redução na infiltração da água da chuva, o aumento do pico de vazão de cheia, a antecipação 
no tempo desta vazão máxima até uma seção de destino e o aumento do volume escoado sobre a superfície, levando ao aumento na frequência de inundações no meio urbano (JHA et al., 2012; CE, 2012).

Uma das maiores deficiências nas cidades é a coleta de resíduos, devido à alta taxa de descarte de resíduos sólidos como restos de construção civil, lixo doméstico, móveis velhos em locais inapropriados podem causar problemas na ordem de saúde pública, dependendo do tipo de resíduo que se acumula em determinados ambientes, pode haver a proliferação vetores como ratos, artrópodes, mosquitos e consequentemente aumento de casos de doenças relacionadas a estes animais.

O mosquito Aedes aegypti ou o Aedes albopictus, vetor do arbovírus da dengue, que apresenta grande capacidade de adaptação a criadouros artificiais como caixas d'água, latas, pneus ou qualquer local que possa acumular água, possibilita epidemias em cidades devido ao seu hábito antropofílico (VALLE et al., 2015). Geralmente, as altas taxas de infecção estão relacionadas a locais com pouco saneamento, próximos as aglomerações de resíduos, próximo a lixões ou aterros sanitários. De acordo com Natal et al. (2005), umas das alternativas mais adequadas para minimizar esses problemas é a construção de aterros controlados ou lixões em pontos próximos, fora do perímetro urbano e administrados de acordo com as normas estabelecidas.

Outro ponto importante sobre os serviços de saneamento no ambiente urbano são as redes de esgoto doméstico. $O$ não atendimento a condições básicas de saneamento acarreta a exposição direta de indivíduos a situações de risco, sobretudo em relação doenças infectocontagiosas. Camargo et al. (2017) apresenta uma lista de doenças relacionadas ao saneamento básico, ou seja, doenças que são transmitidas por meio da ingestão de água contaminada, contato com resíduos ou solos contaminados, ou a partir de parasitas ou mosquitos, desta lista, destacam-se: amebíase, ascaridíase, cisticercose, cólera, dengue, diarreia, esquistossomose, giardíase, hepatite, entre outras.

\section{Febre Chikungunya}

A palavra Chikungunya vem da língua Makonde, originaria da Tanzânia, e significa, literalmente, 'aquele que se dobra pra cima'. Esse nome foi adotado para denominação da doença, pois as dores da artrite causada pelo vírus fazem com que os indivíduos infectados se curvem para cima (WANG et al., 2011). A Chikungunya é geralmente transmitida pelo mosquito Aedes aegypti, o mesmo transmissor de doenças como a Dengue, do vírus Zika, e a febre Oropouche. Este mosquito se adapta melhor a climas quentes, tropicais e subtropicais (COFFEY, 2011). De acordo com Honório (2015), no Brasil o primeiro caso registrado da doença foi em setembro de 2014, na cidade de Oiapoque (AP). Ao longo do citado ano, foram registrados em todo o país 2.772 casos em seis estados diferentes, sendo eles Amapá, Bahia, Distrito Federal, Mato Grosso do Sul, Roraima e Goiás.

\section{A doença}

Segundo Moya et al. (2014), os estudos já realizados abordando o vírus Chikungunya demonstraram que a doença possui duas fases: a aguda e a crônica. A fase aguda é a fase inicial da doença, durando, 
geralmente, de 3 a 10 dias. Os sintomas desse período são: febres altas, dores de cabeça, fadiga, dores musculares intensas, conjuntivite, fotofobia, edemas faciais, náuseas, vômitos, e ainda pode apresentar erupções e lesões dermatológicas nos pés, nas mãos e nas regiões mucosas do corpo. A fase crônica é iniciada quando a pessoa afetada tem dor nas articulações por mais de três meses. A dor pode ser recorrente em uma ou mais articulações, e podem ser de intensidade migratória ou bilateral afetando a qualidade de vida. Têm sido relatadas perturbações do sono e de memória. Os resultados dos estudos de cronicidade da Chikungunya são heterogêneos, uma vez que tem sido feito em países com diferentes contextos.

No entanto, em todos os casos, a dor vai diminuindo gradualmente mês a mês. Honório (2015) alude, ainda, para a possibilidade mesmo que remota de se chegar ao óbito, e deixar sequelas permanentes. As sequelas permanentes mais frequentes estão ligadas a artrites, que pioram significativamente a qualidade de vida do sujeito. Por conta das fortes artrites causadas pela Chikungunya, o indivíduo infectado fica impossibilitado de realizar a movimentação cotidiana. As profundas artrites ocorridas no período sintomático é uma das características que distinguem a Chikungunya da dengue, essas artrites podem permanecer como sequelas permanentes na pessoa infectada (HORCADA et al., 2015).

De acordo com Montero (2014), como ainda não se tem uma vacina para este vírus, a principal maneira de se evitar sua infecção é pela prevenção, evitando que o mosquito se prolifere com ações de profilaxia, tentando evitar lugares onde existem casos registrados, utilizando produtos repelentes de insetos. Recomenda-se também ter cuidado com o uso de perfumes, pois podem atrair os insetos e procurar estar em lugares com ar-condicionado, pois o aparelho inibe a circulação dos insetos neste ambiente.

\section{A relação do saneamento básico e a saúde pública}

Entre as ações de saneamento, destacam-se aquelas consideradas como básicas, compreendendo o abastecimento de águas, o esgotamento sanitário, a limpeza pública e a drenagem de águas pluviais, uma vez que a ausência desses serviços tem resultado em precárias condições de saúde de uma parcela significativa da população brasileira, com a incidência de doenças, principalmente de veiculação hídrica, tais como diarreias, hepatite, cólera, amebíase, febre tifoide e esquistossomose, entre outras (MOTA, 2005).

Dados do ITB (2015) indicam que $83 \%$ dos brasileiros são atendidos com abastecimento de água tratada, e 50,3\% da população têm acesso à coleta de esgoto. E mesmo tendo redes coletoras disponíveis, as maiores cidades despejam esgoto irregularmente no ambiente. Ainda em relação ao tratamento de esgoto, a região com melhor desempenho, é o Centro-Oeste com $50,22 \%$ do esgoto tratado; em seguida vem Sudeste, com 47,39\%; Sul, com 41,43\%; Nordeste, com apenas 32,11\%; e Norte apenas $16,42 \%$.

Segundo Mota (2005), a melhor forma de prevenir muitas doenças é garantir à população um ambiente que the proporcione as condições básicas de vida, com abastecimento de água potável e gestão adequada dos resíduos. As atividades de saneamento integram as ações de saúde pública, pois visam à saúde da população, em seu sentido mais amplo através de mecanismos de prevenção a incidência de doenças.

Mota (2005) define Saúde Pública como a ciência e a arte de evitar doenças, prolongar a vida e desenvolver a saúde física, mental e eficiência. Por meio de esforços organizados da comunidade visando o 
saneamento do meio ambiente, o controle de infecções na comunidade, a organização de serviços médicos e paramédicos, o diagnóstico e tratamento precoce de doenças. É importante ressaltar a importância da educação ambiental nos programas de saneamento, uma vez que sem a participação da população dificilmente eles obterão êxito desejado.

\section{MATERIAIS E MÉTODOS}

\section{Caracterização da área de estudo}

O estudo foi realizado no Bairro da Matinha localizado entre as coordenadas geográficas $2^{\circ} 28^{\prime} 22.90$ e $2^{\circ} 28^{\prime} 23.50^{\prime \prime}$ latitude Sul e $54^{\circ} 44^{\prime} 16.10^{\prime \prime}$ e $54^{\circ} 44^{\prime} 16.70^{\prime \prime}$ longitude Oeste, munícipio de Santarém (PA), conforme se pode visualizar na figura 1. A coleta de dados ocorreu nos meses de outubro e novembro de 2017.

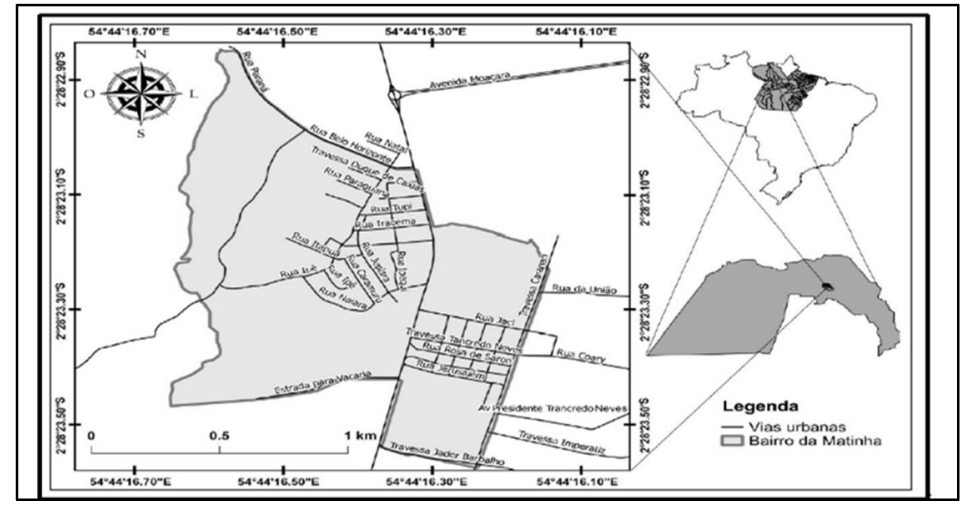

Figura 1: Mapa da Localização da área de estudo.

O Bairro possui 1.697 domicílios com aproximadamente 4.066 habitantes (IBGE, 2010). Segundo informações repassadas pela associação de moradores, o Bairro da Matinha começou a ser habitado no início da década de 70, e se expandiu após o asfaltamento da BR-163. A rodovia é a principal via de acesso a parte central e rural de Santarém. As principais atividades socioeconômicas do bairro são referentes a indústria madeireira, minimercados, lojas de autopeças, comércio de material de construção civil. De acordo com Donato (2010), as condições de moradia, e abastecimento de água são precárias no local. Além disso, a geomorfologia de uma parte do bairro conta com a presença de uma serra, sendo que o bairro expandiu em direção a mesma, com ocupação em áreas com alto risco de deslizamentos (figura 2).

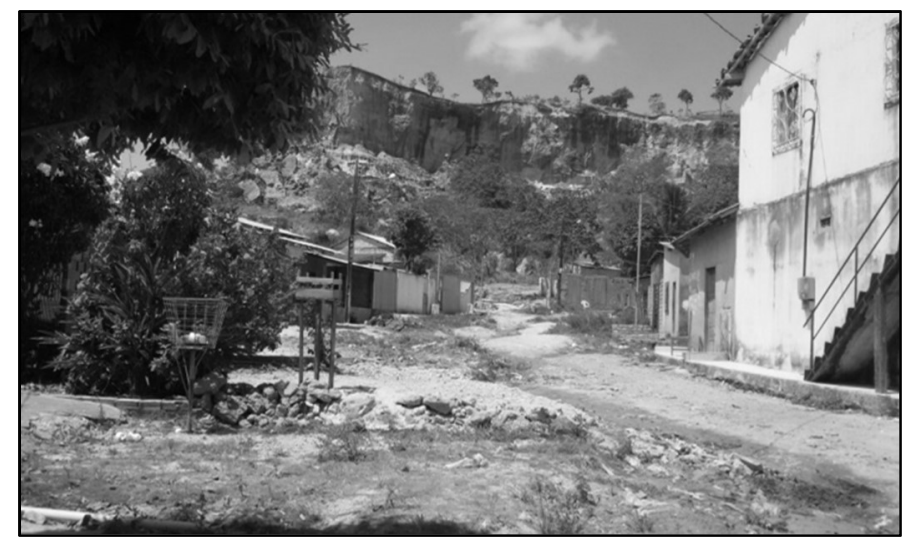

Figura 2: Ocupação em área de risco na Rua Naiara. 


\section{Coleta de dados}

Para a coleta de dados, utilizou-se uma abordagem quanti-qualitativa com a utilização de observação in loco, aplicação de questionários, registros fotográficos e análise de dados secundários como instrumentos de pesquisa. A pesquisa foi dividida em três fases, sendo a primeira a aplicação de 183 questionários fechados, seguindo o seguinte critério: ruas com maior número de casos confirmados. Esta opção de questionário, embora restrinja a liberdade das respostas, facilita o trabalho do pesquisador e também a tabulação, pois as respostas são mais objetivas com questões de múltipla escolha: são perguntas fechadas, mas que apresentam uma série de possíveis respostas, abrangendo várias facetas do mesmo assunto, sendo o método mais adequado ao objetivo do presente estudo (MARCONI et al., 1999).

O questionário foi composto por 17 perguntas, sendo estas referentes à escolaridade, tempo de residência no local, composição familiar, coleta de lixo, conhecimentos sobre terrenos baldios existentes na área, casos confirmados de Dengue e Chikungunya na família, orientações de saúde, a importância das ações de prevenção das doenças e nível de conhecimento sobre Saneamento Básico. Na ocasião, foram percorridas as ruas pertencentes ao bairro, efetuando uma análise visual das vias, imóveis e terrenos baldios, destacando as problemáticas e verificando a presença de depósitos inadequados de resíduos sólidos e a condição das infraestruturas de saneamento.

Na segunda etapa da pesquisa, analisou-se os dados secundários do Sistema de Informação de Agravos de Notificação (SINAN). Os dados coletados são relacionados ao número de casos de febre Chikungunya notificados e confirmados no município em 2017, assim como os principais bairros afetados, período de ocorrência e localização dos logradouros com maior incidência da doença. Para acesso aos mesmos, foram encaminhados a Secretaria Municipal de Saúde (SEMSA), um ofício e um Termo de Compromisso de Utilização de Dados (TCUD), para a então liberação de informações do SINAN vinculado ao Centro de Controle de Zoonoses (CCZ). Após a coleta dos dados, iniciou-se a tabulação e à confecção de gráficos utilizando o programa Microsoft Excel, para posterior análise dos resultados.

\section{RESULTADOS E DISCUSSÃO}

\section{Perfil dos moradores e percepção sobre as condições do saneamento no Bairro da Matinha}

A pesquisa através dos questionários alcançou um total de 722 pessoas, o que equivale aproximadamente a $18 \%$ de habitantes do bairro. Verificou-se que a maioria dos entrevistados possui o ensino fundamental incompleto, conforme se vê a proposição na figura 3, que traz sete categorias de escolaridade.

O bairro, em sua maioria, é atendido com a coleta de resíduos sólidos, realizada três vezes na semana, dado confirmado por $92 \%$ dos entrevistados. No entanto, $11 \%$ dos que são atendidos informaram estarem insatisfeitos com o serviço, pois acreditam que o mesmo deveria ser realizado diariamente; $8 \%$ dos entrevistados responderam não ter acesso a este serviço devido à localização das residências ser em uma área de encosta, com vias de difícil acesso, o que compromete a circulação dos veículos coletores. Estes, ao 
serem questionados sobre qual seria então a destinação final dada aos resíduos produzidos em suas residências afirmaram que realizam a queima, o que é proibido por legislação municipal e federal (figura 4).

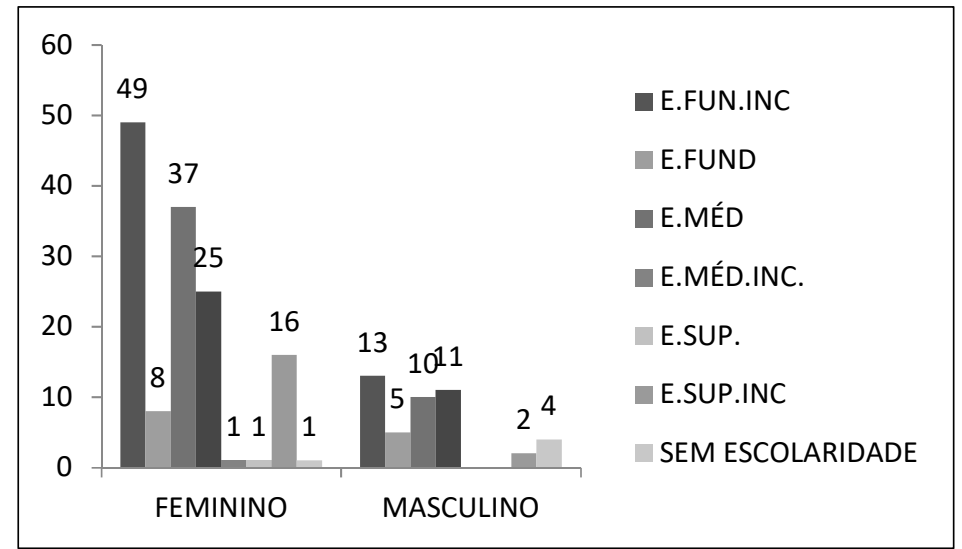

Figura 3: Dados sobre gênero e nível de escolaridade dos entrevistados.

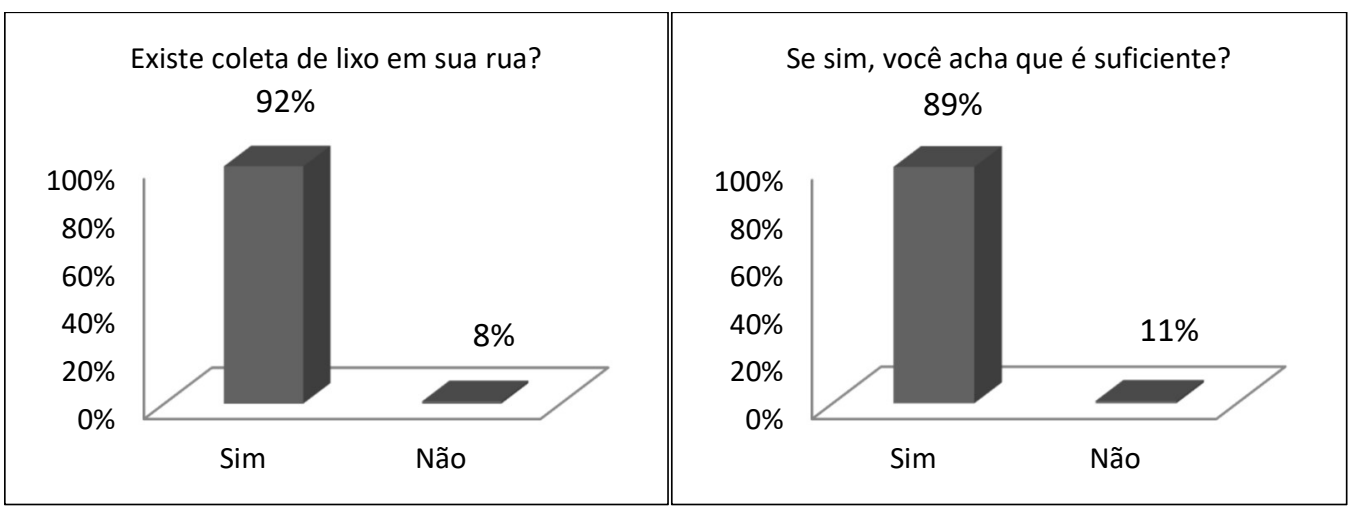

Figura 4: Dados sobre a coleta de resíduos.

Dos entrevistados, 32\% afirmaram a existência de terrenos baldios próximos de suas residências, e 95\% destes acham que esses terrenos contribuem para a disseminação de doenças, uma vez que estão sendo utilizados como depósito inadequado de resíduos sólidos domiciliares (figura 5). A problemática se torna ainda maior no período chuvoso devido ao acúmulo de água que serve como criadouro para o mosquito Aedys Aegypit.

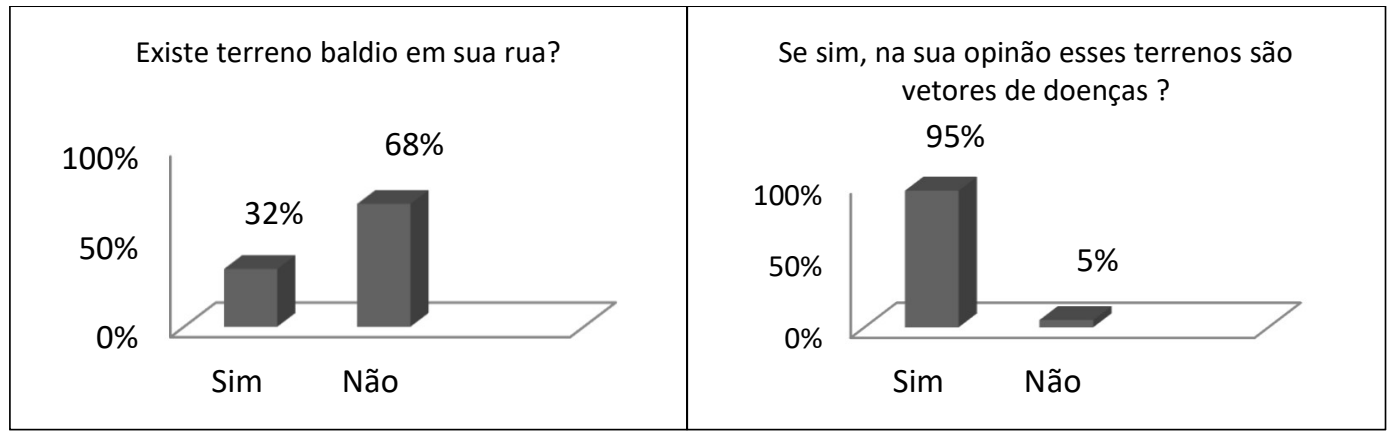

Figura 5: Dados sobre a presença de terrenos baldios.

Evidencia-se que o Código de Postura do Município de Santarém (Lei no19.207/2012), estabelece que, para assegurar a melhoria das condições de vida da população, compete à Prefeitura a limpeza dos terrenos localizados na zona urbana. $\mathrm{O}$ capítulo $\mathrm{V}$ do referido código, art. 74 , cita que os proprietários, inquilinos ou outros usuários dos terrenos não edificados, localizados na zona urbana, são obrigados a mantê- 
los cercados, roçados ou capinados, limpos e drenados. $\mathrm{O}$ art. 75 expõe que é proibido depositar, despejar ou descarregar lixo, entulhos ou resíduos de qualquer natureza, em terrenos localizados na zona urbana do Município, mesmo que aquele esteja fechado e estes se encontrem devidamente acondicionados.

\section{Incidência de Dengue e Chikungunya e relação com saneamento}

Dentre os entrevistados, 15 pessoas afirmaram já ter contraído a Chikungunya, e 30 foram acometidos pela dengue. Entre os entrevistados que contraíram Chikungunya, 7 afirmaram que haviam viajado para outra localidade, antes de serem acometidos da doença, conforme dados trazidos e ilustrados na figura 6. Segundo dados disponibilizados pelo SINAN, na área urbana do município de Santarém foram notificados 109 casos, e destes, 35 casos foram confirmados. Por outro lado, na zona rural foram notificados 9, com apenas 1 caso confirmado, conforme se apresenta na Tabela 1.
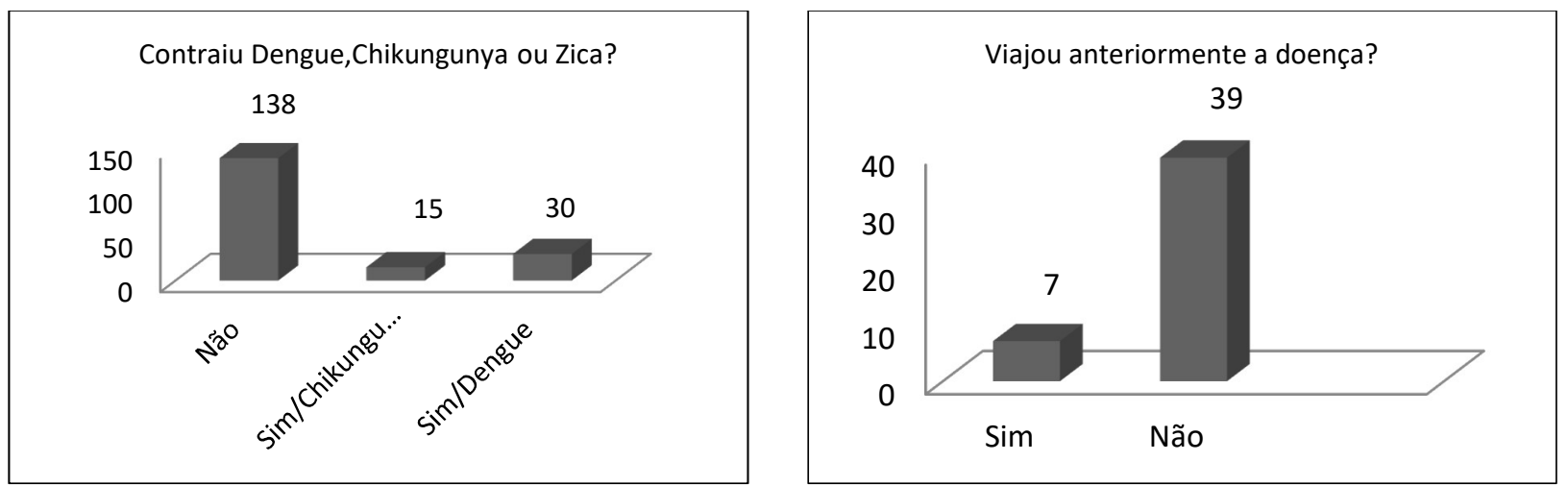

Figura 6: Incidência de Dengue e Chikungunya no Bairro da Matinha.

Tabela 1: Casos de febre Chikungunya no período entre 01 de janeiro a 31 de outubro de 2017.

\begin{tabular}{|c|c|c|c|}
\hline \multicolumn{2}{|c|}{ Notificados } & \multicolumn{2}{c|}{ Confirmados } \\
\hline Zona Residência & 2017 & Zona Residência & 2017 \\
\hline Urbana & 109 & Urbana & 35 \\
\hline Rural & 09 & Rural & 01 \\
\hline Total & $\mathbf{1 1 8}$ & Total & $\mathbf{3 6}$ \\
\hline
\end{tabular}

Entre os casos confirmados, 6 foram do sexo masculino e 30 do feminino, sendo que a maior parte dos infectados tem em média entre 20 e 60 anos de idade. Todos os casos confirmados de Febre Chikungunya foram curados, pois os pacientes são acompanhados durante todo o tratamento e recebem regularmente a visita dos agentes de endemias, que repassam orientações para prevenção de doenças. Oliveira et al. (2014), em estudo feito na cidade de Montes Claros (MG), também observou que a zona com maior número de casos confirmados foi a área urbana. Em 2012, 1.117 casos na zona urbana e 10 casos na zona rural e, em 2013 com 5.168 da zona urbana e 98 na zona rural.

Dos 118 casos notificados, foram confirmados apenas 36 casos de febre Chikungunya no município. A maior incidência de casos notificados, ocorreu entre os meses de março e julho, sendo que o mês de maio apresentou o número mais alto (41 casos) de ocorrências, como se pode ver na figura 7. Percebe-se que a maior incidência ocorreu no período chuvoso que favorece a proliferação do mosquito Aedes Aegypit.

Segundo Corrêa et al. (2016), em um estudo sobre a incidência de Dengue em municípios do estado do Pará, a variabilidade temporal da precipitação influência de modo heterogêneo e que a incidência da 
doença é resultado da combinação de vários fatores que contribuem para sua proliferação, como a coleta de resíduos sólidos deficiente, densidade populacional alta, habitações sem água encanada e com recipientes inadequados de armazenamento e condições socioeconômicas precárias. Na tabela 2 são apresentados os casos de febre Chikungunya registrados nos bairros de Santarém no período de janeiro a outubro de 2017.

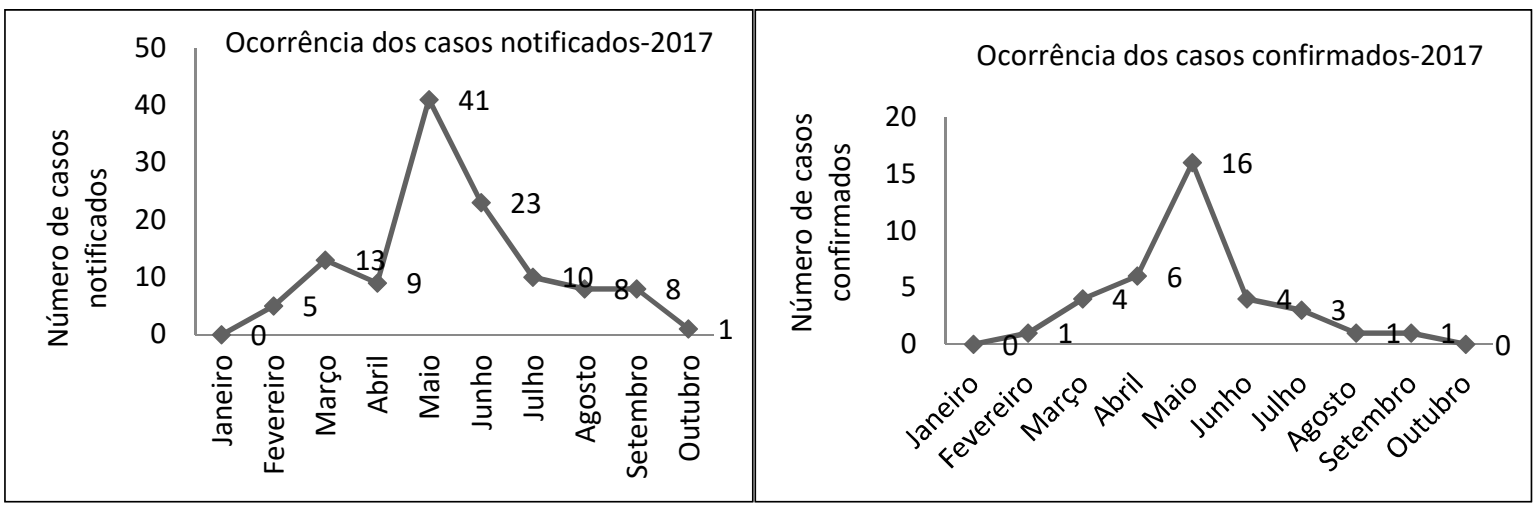

Figura 7: Ocorrência de Chikungunya entre janeiro e outubro de 2017.

Tabela 2: Casos de Febre Chikungunya nos bairros de Santarém entre 01 de janeiro e 31 de outubro de 2017.

\begin{tabular}{|c|c|c|c|c|c|}
\hline \multicolumn{2}{|c|}{ Número de Casos Notificados } & Bairros & \multicolumn{2}{c|}{ Número de Casos Confirmados } \\
\hline Bairros & Total & Nova república & 7 & Maracanã & 2 \\
\hline Alvorada & 1 & São Francisco & 3 & Laguinho & 1 \\
\hline Amparo & 1 & Vitória Régia & 1 & Caranazal & 1 \\
\hline Elcione Barbalho & 1 & Prainha & 1 & Aparecida & 2 \\
\hline Maracanã & 5 & Santana & 2 & Jardim Santarém & 1 \\
\hline Santarenzinho & 3 & Santíssimo & 2 & Aeroporto velho & 2 \\
\hline São Cristóvão & 1 & Uruará & 1 & Diamantino & 2 \\
\hline Fátima & 1 & Área verde & 1 & Matinha & 18 \\
\hline Laguinho & 2 & Livramento & 2 & Nova República & 1 \\
\hline Liberdade & 2 & Maicá & 1 & São Francisco & 1 \\
\hline Mapirí & 2 & Mararu & 2 & Santana & 1 \\
\hline Salé & 2 & São José Operário & 1 & Santíssimo & 1 \\
\hline Caranazal & 2 & Alter do chão & 1 & São José operário & 1 \\
\hline Centro & 2 & Residencial Salvação & 3 & Alter do Chão & 1 \\
\hline Aparecida & 9 & Colônia Boa fé & 1 & Residencial Salvação & 1 \\
\hline Jardim Santarém & 9 & Colônia Poços das Antas & 1 & - & - \\
\hline Aeroporto velho & 7 & Com. Surubi Miri & 1 & - & - \\
\hline Diamantino & 6 & Com. Jacamim & 1 & - & - \\
\hline Interventoria & 2 & Com. Pedra Branca & 1 & - & - \\
\hline Floresta & 1 & Com. Amapá & 1 & Total Confirmados & $\mathbf{3 6}$ \\
\hline Matinha & 25 & 118 & &
\end{tabular}

Observou-se que os maiores índices de casos notificados foram nos bairros Maracanã com 5 casos, Diamantino com 6, Aeroporto Velho 7, Nova República 7, Aparecida 9, Jardim Santarém 9, e Matinha com 25 casos. Os bairros com maior incidência de casos confirmados foram Maracanã, Aparecida, Aeroporto Velho e Diamantino, 2 casos em cada bairro, e Matinha com 18 casos. Observa-se que o bairro Matinha é o bairro mais afetado com a febre Chikungunya, tanto em número de notificados, quanto confirmados.

Em relação a percepção dos moradores quanto ao Saneamento Básico, 58\% dos entrevistados responderam saber o que é o Saneamento básico, e destes $99 \%$ afirmaram que a ausência dos serviços e suas infraestruturas que compõem o saneamento como o Abastecimento de água, Coleta e Tratamento de esgoto, Coleta de Resíduos Sólidos e Drenagem urbana, podem interferir na saúde da população (Figura 8). 


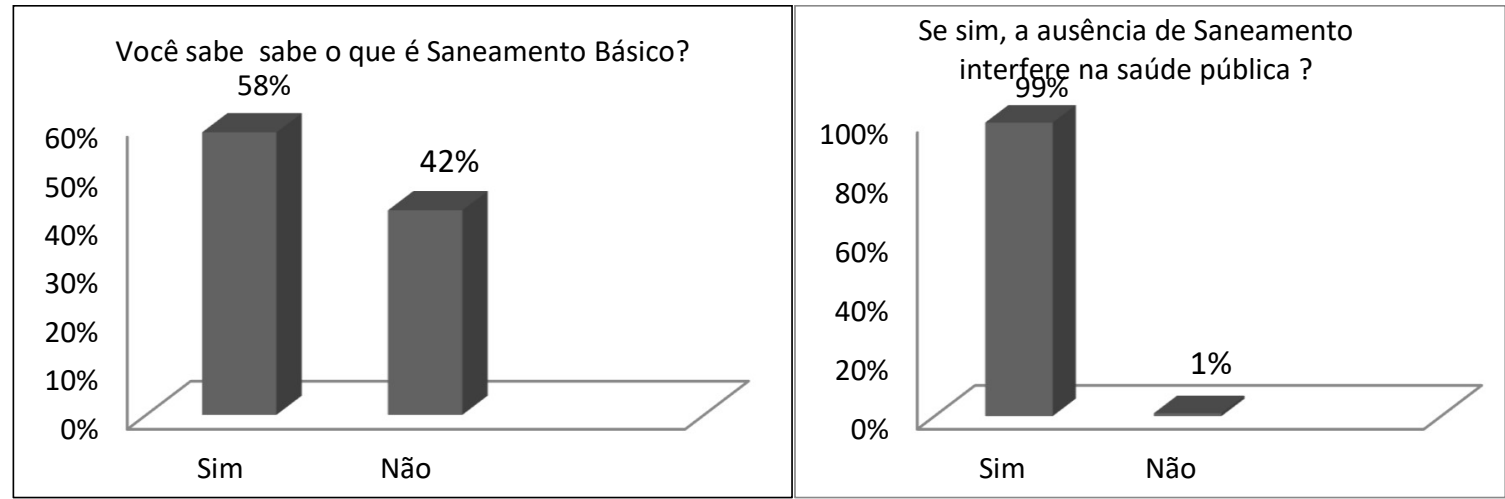

Figura 8: Dados sobre Saneamento Básico.

Por outro lado $42 \%$, dos entrevistados não souberam definir o que é o Saneamento Básico, esse resultado possivelmente está relacionado ao grau de escolaridade dos entrevistados, pois a maioria dos participantes possui apenas o ensino fundamental incompleto. Diante desse cenário, observa-se a importância do acesso à informação por meio da educação ambiental formal e não formal como forma de sensibilizar a população. Aproveitou-se a oportunidade para se fazer um breve esclarecimento sobre os serviços e infraestrutura de saneamento básico e sua importância para qualidade de vida da população.

Investigou-se, ainda, quais ações os moradores costumavam executar para evitar a proliferação e transmissão de doenças. A maioria informou que realiza a limpeza dos quintais e evita o acúmulo de água. Foi observado também que os resíduos destinados à coleta são armazenados em sacos plásticos frágeis e suscetíveis ao rompimento pelo excesso de peso e pelo contato de animais. Grande parcela dos resíduos foram depositados fora do horário de coleta, ficando assim expostos a intempéries do tempo como vento e chuva.

Na figura 9, apresenta-se a localização das ruas e o número de casos de Chikungunya detectados de janeiro a outubro de 2017 no Bairro da Matinha. As ruas Naiara, Beco Cuiabá e Av. Cuiabá foram as que apresentaram maior número de infectados, uma vez, que existem diversos terrenos baldios e sarjetas com esgoto doméstico escoando a céu aberto, o que pode ter contribuído para o alto índice de casos no bairro. Além disso, existem ainda os locais de difícil acesso, onde o veículo coletor de resíduos não consegue trafegar para realizar o serviço, favorecendo o acúmulo de resíduos ou a disposição inadequada em terrenos baldios.

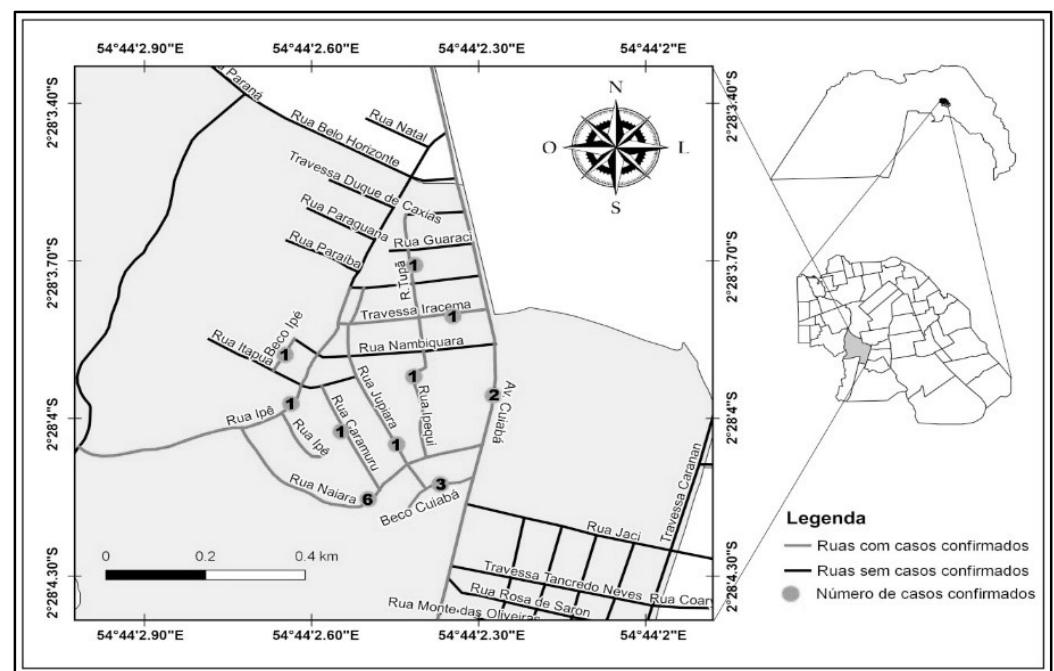

Figura 9: Mapa da Localização dos pontos afetados com a Febre Chikungunya. 
Durante as visitas in loco, observou-se também que o bairro apresenta uma deficiência nos sistemas de drenagem urbana e pavimentação das ruas. Destacam-se a não existência de dispositivos de como bocas de lobo, sarjeta, galerias nas ruas e sumidouros nas residências para captar e destinar as águas pluviais e esgoto doméstico (proveniente das atividades de limpeza da residência), os quais são destinadas diretamente para as vias públicas. Tal situação provoca erosão, odor desagradável e cria ambientes favoráveis à proliferação de vetores de doença (figuras 10 e 11).

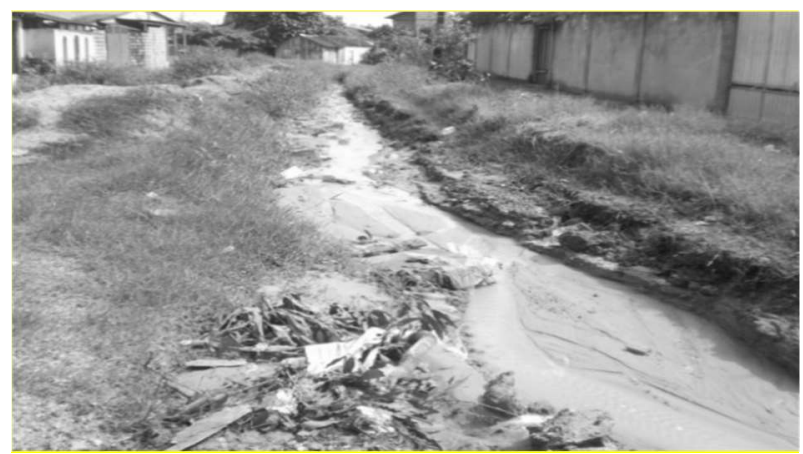

Figura 10: Péssimas condições da Rua Jupiara.

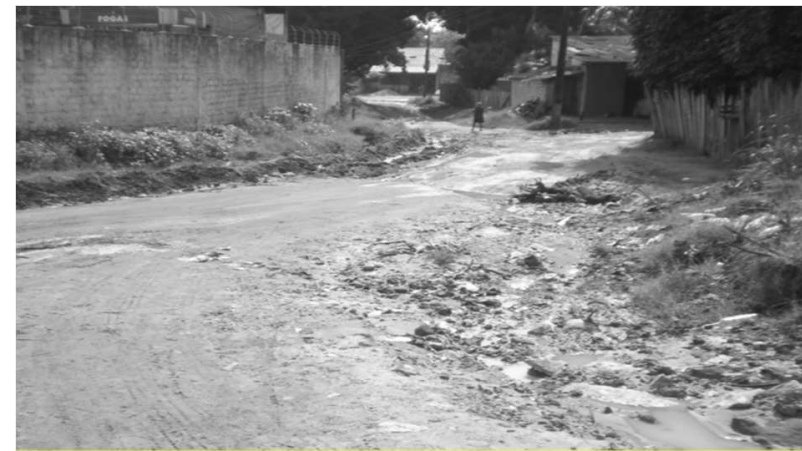

Figura 11: Acúmulo de água na Rua Itapuã.

Evidencia-se que o bairro possui muitos problemas de infraestrutura urbana como ruas não pavimentadas, ausência de sistema de drenagem (bueiros) e ausência de rede de coleta de esgoto (figura 12). Em muitos domicílios visitados, os moradores sofrem com a falta de água, tendo que armazená-la em recipientes inadequados e sem tampa, propiciando o ambiente favorável para a proliferação do Aedes aegypti.

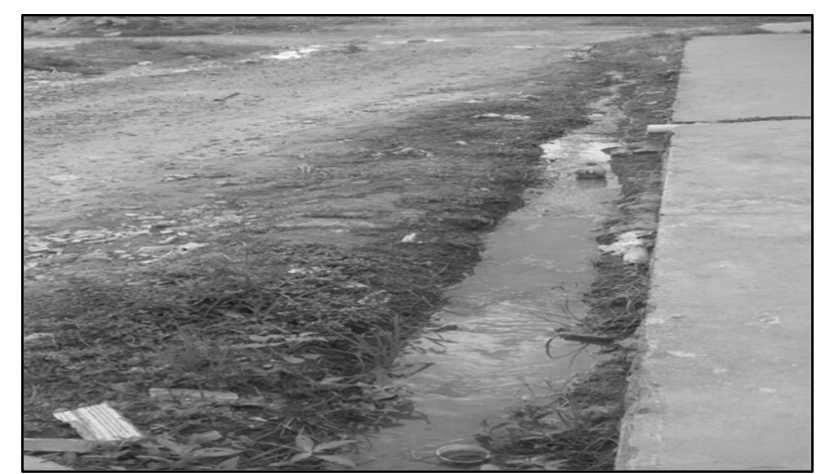

Figura 12: Presença de esgoto escoando a céu aberto na Rua Nanbiquara.

Bovolato (2010), em estudo desenvolvido no Bairro da Matinha, mostra que o principal anseio da população é a infraestrutura geral, como asfalto, saneamento básico, iluminação pública; com destaque ao abastecimento de água eficaz, pois o abastecimento feito pelo poder público não alcança todo o bairro, fazendo com que a população construa coletivamente poços artesianos (microssistema) e as redes de distribuição.

Ressalta-se que os moradores recebem regularmente as visitas tanto dos Agentes de Endemias, quanto dos Agentes Comunitários de Saúde, para orientação e são conscientizados sobre a importância das ações de prevenção e controle das doenças. A partir das informações obtidas, observou-se que as condições socioeconômicas, a carência das infraestruturas de saneamento e o baixo nível de escolarização podem explicar o alto índice de doenças endêmicas, especialmente a Chikungunya, no bairro da Matinha. 


\section{CONSIDERAÇÕES FINAIS}

A partir do estudo verificou-se que os serviços de saneamento do bairro da Matinha estão precarizados, situação esta recorrente no município de Santarém. Nas ruas com casos confirmados de febre Chikungunya observou-se a presença de esgoto escoando a céu aberto, resíduos sólidos, péssimas condições das ruas e o alto número de terrenos baldios sendo utilizados como depósitos inadequados de resíduos que servem como criadouros para o mosquito Aedes Aegypti

Pode-se perceber que, no cotidiano, as pessoas ainda não estão conscientes e sensibilizadas sobre o impacto da falta de saneamento na saúde. Mesmo recebendo as orientações dos profissionais de saúde, alguns moradores não põem em prática as informações que os foram repassadas. Eles não conseguem identificar e tentar sanar as principais causas das enfermidades que os levam em busca de atendimento em hospitais e postos de saúde. Ainda permanecem priorizando o tratamento das doenças e detrimento a prevenção, o que dificulta a erradicação da doença.

A realidade observada nos mostra a importância da presença e qualidade dos serviços de saneamento básico e conscientização/sensibilização dos moradores, discutindo estratégias de melhorias junto a população do bairro que conhecem e convivem com as deficiências existentes, estabelecendo a responsabilidade compartilhada entre o poder público e a comunidade local.

\section{REFERÊNCIAS}

ALBUQUERQUE, I. S. C.. Chikungunya vírus infection: reporto of the first case diagnosed in Rio de Janeiro, Brazil. Revista da Sociedade Brasileira de Medicina Tropical, v.45, n.1, p.128-129, 2012.

ARAGÃO, R.; CRUZ, M.; CORREIA, E.; MACHADO, L. F. Impacto do Uso do Solo pelo aumento da Densidade Populacional sobre o escoamento numa área urbana do Nordeste brasileiro via Geotecnologias e Modelagem hidrológica. Revista Brasileira de Geografia Física, v.10, n.2, p.543-557, 2017.

AYOAD, J. O.. Introdução à climatologia para os trópicos. São Paulo: Bertrand Brasil, 1996.

AZEVEDO, R. S. S.; OLIVEIRA, C. S.; VASCONCELOS, P. F. C.. Risco do Chikungunya para o Brasil. Revista de Saúde Pública, v.49, n.58, p.1-6, 2015.

BRASIL. Constituição da República Federativa do Brasil de 1998. Brasília: DOU, 1998.

BRASIL. Lei n.11445 de 5 de janeiro de 2007. Estabelece diretrizes nacionais para o saneamento básico; altera as Leis nos 6.766, de 19 de dezembro de 1979, 8.036, de 11 de maio de 1990, 8.666, de 21 de junho de 1993, 8.987, de 13 de fevereiro de 1995; revoga a Lei n.6528, de 11 de maio de 1978; e dá outras providências. Brasília: DOU, 2007.

BRASIL. Ministério da Saúde. Boletim Epidemiológico. Brasília: MS, 2015.

BRASIL. Ministério da Saúde. Febre de chikungunya: manejo clínico. Brasília: MS, 2015.
BRASIL. Ministério da Saúde. Manual de Saneamento. Brasília: MS, 2006.

CAMARGO, D. M.; SOUZA, N. M.; PACHECO, T. C. K. F.; ALCÂNTARA, G. C.; DOTA, E. M.. Modelagem geoespacial para identificação de áreas vulneráveis ao contágio por doenças relacionadas a falta de saneamento: o caso da Região Metropolitana de Campinas. Revista Brasileira de Cartografia, v.69, n.3, p.561-573, 2017.

CE. Comissão Europeia. Orientações sobre as melhores práticas para limitar, atenuar ou compensar a impermeabilização dos solos. Bruxelas: Ambiente, 2011.

COFFEY, L. L.. Arbovirus high fidelity variant loses fitness in mosquitoes and mice. PNAS, v.108, n.38, p.16038-16043, 2011.

DONATO, A. V. M.. Expansão Urbana e Periferização em Santarém-PA: estudo sobre o vetor da rodovia CuiabáSantarém (BR-163). ENCONTRO NACIONAL DOS GEÓGRAFOS, 16. Anais. Porto Alegre: AGB, 2010.

GUIMARÃES, A. J. A.; CARVALHO, D. F.; SILVA, L. D. B.. Saneamento básico. Rio de Janeiro: UFRJ, 2007.

HONÓRIO, N. A.. Chikungunya: uma arbovirose em estabelecimento e expansão no Brasil. Cadernos de Saúde Pública, v.31, n.5, p.906-908, 2015.

HORCADA, M. L.; DIÁZ-CALDERÓN, C.; GARRIDO, L.. Febre Chikungunya: Manifestaciones reumáticas de una infección emergente em Europa. Reumatologia Clínica, v.11, n.3, p.161-164, 2015. 
ITB. Instituto Trata Brasil. Ranking do Saneamento Básico no Brasil. São Paulo: ITB, 2015.

JHA, A. K.; BLOCH, R.; LAMOND, J.. Cidades e inundações: um guia para a Gestão Integrada do Risco de Inundação Urbana para o Século XXI. São Paulo: GFDRR, 2012.

MARCONI, M. A.; LAKATOS, E. M.. Técnicas de pesquisa. São Paulo: Atlas, 1999.

MONTERO, A.. Fiebre Chikungunya: una nueva amenaza global. Medicina Clínica, v.145, n.3, p.118-123, 2014.

MOTA, F. S. B.. Conhecimentos para a Promoção do Saneamento, Saúde e Ambiente. In: PHILIPPI JUNIOR, A.. Saneamento, saúde e ambiente: Fundamentos para um desenvolvimento sustentável. Barueri: Manole, 2005.

MOYA, J.; PIMENTEL, R.; PUELLO, J.. Chikungunya: um reto para los serviços de salud de la República Dominicana. Revista Panamericana de Salud Pública, v.36, n.5, p.331-335, 2014.

NATAL, D.; MENEZES, R. M. T.; MUCCI, J. L. N.. Fundamentos da Ecologia Humana. In: PHILIPPI JUNIOR, A.. Saneamento, saúde e ambiente: Fundamentos para um desenvolvimento sustentável. Barueri, SP: Manole, 2005.

OLIVEIRA, R. S.; MARTINS, I. M. L.; OLIVEIRA, A. B.; SANTOS, J. C; DUARTE, V. V.; LOPES, T. R. C.; OLIVEIRA, E. M. S.; OTTONI, M. A. M.. Perfil demográfico dos casos de dengue notificados em Montes Claros, MG em 2010-2013. Revista Digital, n.189, 2014.

PEREIRA, C. F.; FERREIRA, T. G.; BORGES, J. L.. Política de saúde e controle da dengue em Uberaba-MG. Revista Eletrônica Univar, v.1, p.90-95, 2013.
PHILIPPI JUNIOR, A.. Saneamento, saúde e ambiente: fundamentos para um desenvolvimento sustentável. Barueri: Manole, 2004.

PHILIPPI JUNIOR, A.; MALHEIROS, T. F.. Saneamento e Saúde Pública: Integrando Homem e Ambiente. In: PHILIPPI JUNIOR, A.. Saneamento, saúde e ambiente: Fundamentos para um desenvolvimento sustentável. Barueri: Manole, 2005.

PHILIPPI JUNIOR, A.; SALES, C. P.; SILVEIRA, V. F.. Saneamento do Meio em emergências Ambientais. In: PHILIPPI JUNIOR, A.. Saneamento, saúde e ambiente: Fundamentos para um desenvolvimento sustentável. Barueri: Manole, 2005.

RIBEIRO, A. S.; AMARAL, F. O. M.; SILVA, J. M.; COSTA, L. A.; OLIVEIRA, V. F. M.. Cidade Sustentável, bem-estar para todos: uso e ocupação do solo e seus impactos ambientais. Palmas: MP/TO, 2011.

ROBAINA, L. E. S.; KORMANN, T. C.; WIGGERS, M. M.; SCCOTI, A. A. V.. Análise espaço-temporal das ocorrências de inundações e movimentos de massa no município de Caxias do Sul, RS. Ciência e Natura, v.32, n.1, p.159-172, 2010.

SANTOS, A. R.. Enchentes e deslizamentos: causas e soluções. São Paulo: Pini, 2012.

SCANDAR, S. A. S.. Febre de Chikungunya 'Aqueles que se dobram'. Informativo SUCEN, n.11, 2012.

VALLE, D.; PIMENTA, D. N.; CUNHA, R. V.. Dengue: teorias e práticas. Rio de Janeiro: FOC, 2015.

WANG, D.; SUHRBIER, A; NICHOLSON, A. P.. A Complex adenovírus vaccine against chikungunya virus provides complete protection against viraemia and arthritis. National Institutes of Health, v.29, n.15, p.2803-2809, 2011.

A CBPC - Companhia Brasileira de Produção Científica (CNPJ: 11.221.422/0001-03) detém os direitos materiais desta publicação. Os direitos referem-se à publicação do trabalho em qualquer parte do mundo, incluindo os direitos às renovações, expansões e disseminações da contribuição, bem como outros direitos subsidiários. Todos os trabalhos publicados eletronicamente poderão posteriormente ser publicados em coletâneas impressas sob coordenação da Sustenere Publishing, da Companhia Brasileira de Produção Científica e seus parceiros autorizados. Os (as) autores (as) preservam os direitos autorais, mas não têm permissão para a publicação da contribuição em outro meio, impresso ou digital, em português ou em tradução. 